\title{
Tulip Bulb Sign
}

Kushaljit Singh Sodhi, Milli Dutta, Akshay Kumar Saxena, Manphool Singhal, Niranjan Khandelwal

\section{ABSTRACT}

Tulip bulb sign refers to a configuration of the aortic root, in which dilatation of the root of aorta occurs along with effacement of the sinotubular junction. It is characteristically described in annuloaortic ectasia, a common feature of Marfan syndrome.

Keywords: Sign, Tulip bulb, Marfan syndrome, CT scan.

How to cite this article: Sodhi KS, Dutta M, Saxena AK, Singhal M, Khandelwal N. Tulip Bulb Sign. J Postgrad Med Edu Res 2013;47(3):167-168.

Source of support: Nil

Conflict of interest: None declared

\section{INTRODUCTION}

A young 36-year-old man, a known Marfan’s syndrome, presented with complaints of mild chest pain and palpitations of 4 months duration. Multidetector CT (MDCT)
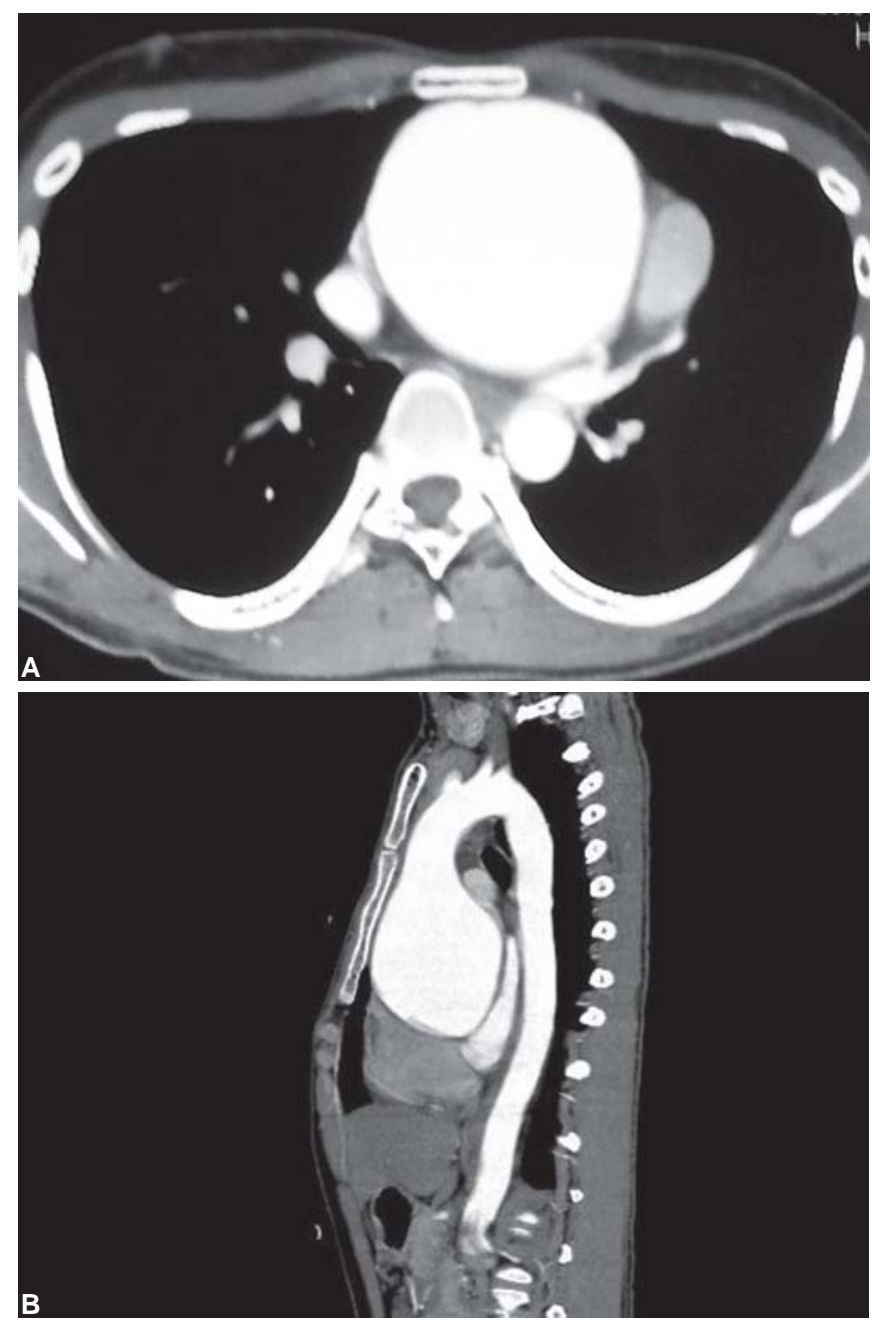

Figs 1A and B: Axial (A) and sagittal (B) contrast-enhanced CT scan reveals gross dilatation of root of aorta angiography was performed on 64-row CT scan (Toshiba: Aquilon system) which revealed gross dilatation of root of aorta (Figs 1 and 2) with obliteration of the sinotubular ridge and its extension into the ascending aorta, features of which were diagnostic for annuloaortic ectasia. Arch of aorta and descending aorta were normal in caliber and course. No evidence of aortic dissection was demonstrated. The root of dilated aorta with a tapering normal aortic arch had a characteristic appearance of 'tulip bulb'.

Tulip bulb sign has been described to refer to a typical configuration of the aortic root, in which dilatation of the root of aorta occurs along with effacement of the sinotubular junction. It is characteristically described in annuloaortic ectasia, which is seen in 60 to $80 \%$ of adults with Marfan syndrome. ${ }^{1,2}$ A characteristic tulip-shaped appearance of the root of dilated aorta is seen with a tapering normal aortic arch, which gives rise to this 'tulip bulb sign'. Pathologically, the aortic wall displays medial degeneration of the elastic tissue with cystic medial necrosis. ${ }^{1,2}$ Accurate demonstration of these anatomical structures is crucial for surgical planning and also for postoperative evaluation.

\section{REFERENCES}

1. Kimura-Hayama ET, Meléndez G, Mendizábal AL, MeaveGonzález A, Zambrana GF, Corona-Villalobos CP. Uncommon congenital and acquired aortic diseases: Role of multidetector CT angiography. Radiographics 2010;30:79-98.

2. Agarwal PP, Chughtai A, Matzinger FR, Kazerooni EA. Multidetector CT of thoracic aortic aneurysms. Radiographics 2009;29:537-52.

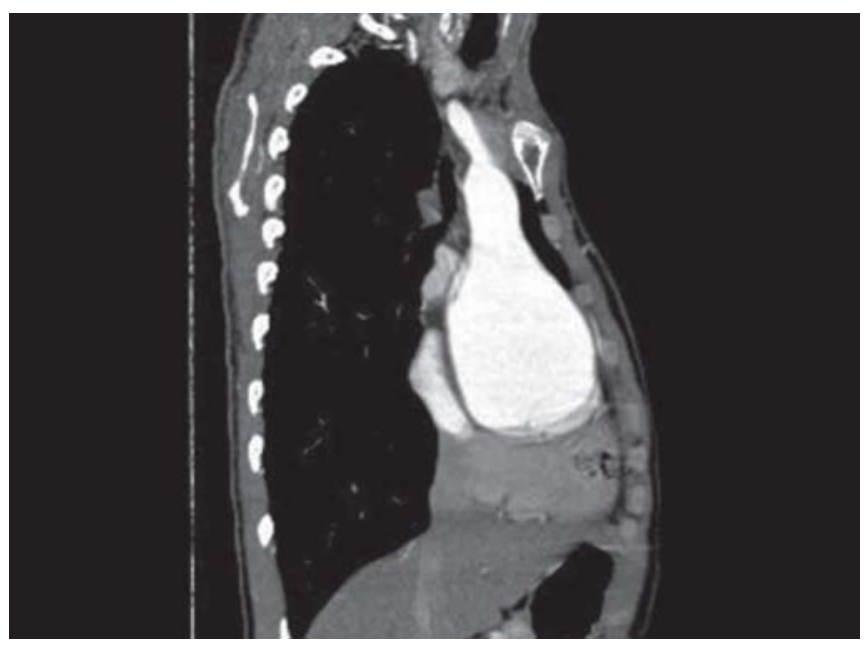

Fig. 2: Reformatted CT image demonstrates dilated aortic root with obliteration of the sinotubular ridge and its extension into the ascending aorta, producing a characteristic appearance of 'tulip bulb sign' 


\section{ABOUT THE AUTHORS}

\section{Kushaljit Singh Sodhi (Corresponding Author)}

Associate Professor, Department of Radiodiagnosis and Imaging Postgraduate Institute of Medical Education and Research, Chandigarh India, e-mail: sodhiks@gmail.com

\section{Milli Dutta}

Senior Resident, Department of Radiodiagnosis and Imaging Postgraduate Institute of Medical Education and Research Chandigarh, India

\section{Akshay Kumar Saxena}

Additional Professor, Department of Radiodiagnosis and Imaging, Postgraduate Institute of Medical Education and Research Chandigarh, India

\section{Manphool Singhal}

Assistant Professor, Department of Radiodiagnosis and Imaging Postgraduate Institute of Medical Education and Research, Chandigarh, India

\section{Niranjan Khandelwal}

Professor and Head, Department of Radiodiagnosis and Imaging Postgraduate Institute of Medical Education and Research, Chandigarh, India 